\title{
Communication technologies and education: lessons in the potential of innovation
}

\author{
Nigel Norman \\ Department of Education, University of Wales Swansea
}

The evaluation of initiatives in using new forms of technology to enhance teaching and learning will raise awareness of the need for a structured and principled approach to the introduction of innovative methods. This paper addresses the pedagogical potential of communication technology for curricular development in schools, initial teacher education and continuing professional development. It establishes principles of practice based on activities undertaken within a national project involving schools and higher-education institutions.

\section{Introduction}

This paper seeks to outline the implications for pupils and teachers of Modern Foreign Languages (MFL) of the use of communication and information technologies (C\&IT). It is based on the experiences of one of the school/university partnerships involved in the BT Initial Teacher Training Communication Technologies Initiative, begun in the autumn term of 1996. By examining examples of projects undertaken with minimal training, it will establish some principles for further development in an area that is manifestly innovative for the majority of those involved in secondary schools.

The BT initial teacher training initiative was primarily designed 'to increase understanding of how communication technologies can enrich teaching and learning' (BT, 1997, 8). Accordingly, the main objectives for the use of communication technologies were:

- as a teaching and learning resource for pupils in the classroom;

- for trainee-to-trainee peer support between the higher-education institutions (HEIs) involved;

- for remote supervision and counselling of trainees by their tutors;

- for remote in-service provision by the HEIs for school staff;

- for BT co-ordination and management of the project.

The communication technologies available were email, Campus World and the Internet, 
fax, telephone, and videoconferencing using PCC VC8000 (ISDN) videoconferencing equipment. In practice, the preferred media proved to be email and (especially) videoconferencing, even though these were generally perceived to be areas in which participants had little or no knowledge or skills. It is with videoconferencing that this paper is primarily concerned.

With objectives that catered for a variety of users (pupils, student teachers, teachers, university tutors), a common initial aim had to be establishing familiarity with and ease of handling of the equipment. Clearly, one has to understand what the equipment is capable of before tapping its pedagogic potential. Training needs dictate that the manual skill of handling the equipment becomes, if not second nature, at least an activity carried out with confidence, and one based on a simple set of working instructions with fail-safe techniques catered for (as, in fact, in any well-prepared lesson). Underlying the whole should be the questions: does this enhance the teaching and learning process? does the technology provide access to different learning experiences? With reference specifically to electronic communications, Davis (1997) indicates the nature of the challenge facing education:

By 1996 electronic communications had proved their value to enhance learning, but most activities have been outside the normal curriculum. In future, the structure of teaching and learning may change to permit communications technologies to play as important a role in education as they do in commerce.

And Mason (in Mason and Bacsich, 1994, 36-7), discussing the educational value of ISDN, a common 'engine' for videoconferencing, sounds a warning but also sees its great potential:

ISDN [. . .] will not totally transform education and training, but what it will do is integrate voice, text and video onto the students' and teachers' desktop. It does provide a very broad base on which to build education and training applications: large-scale videoconferencing, small group co-operative learning, computer-based packages, multimedia interactive sessions, and very fast file exchange and access to learning resources.

\section{Benefits of C\&IT in schools}

The world of education and training may need persuading of the benefits to individual learners of using C\&IT, since there is already evidence that new technologies have simply been used in a traditional transmissive mode, pouring, to use the analogy of Wright and Cordeaux, new wine from old bottles: 'Regarding it simply as a tool to deliver distance lecturing using didactic teaching approaches misses the point. Without a change of emphasis, the major capability of the technology to support learning is excluded' (Wright and Cordeaux, 1996).

The 1996 NCET publication on teacher training and computer-mediated communications (CMC) (NCET, 1996) outlines the potential benefits to teachers and learners in terms of collaboration, autonomy and support: peer group interaction, self-paced work, and access to peer and tutor advice almost on demand. It emphasises the role that CMC has to play as a support mechanism in professional development and training, referring to Mason (1994) who identified in particular the following: 
- enhanced tutorial support;

- a forum for interaction between teachers and learners;

- a medium for mutual support;

- access to expert debate;

- a teaching medium;

- course delivery.

Of these, the single and most palpable enhancement achieved through videoconferencing is simultaneous face-to-face interaction at a distance. In the school context, pupils in one school can link with pupils elsewhere nationally or internationally, exchange information, and develop oral and written skills. Thus five pupils from a Year 8 French class at Cardiff High School talked about themselves and their interests to pupils at Glenwood High School in Scotland, who relayed similar details back - all in French.

On the face of it, this would not seem to suggest much more than a high-speed version of what goes on already, albeit with the added novelty of technology to lend immediacy and excitement. This naturally increases motivation and with it learning. However, the technology has enabled the production of a significant additional motivational factor: a genuine audience. After all, in the standard classroom situation, pupils and teacher know each other, the school, the area and so on - that is, there is familiarity of context. Thus, in the Modern Languages classroom, pupils are continually using the foreign language to ask questions, the answers to which are already known to all concerned. This is language rehearsal, rather than language use. Language is not serving a communicative purpose, but is practising, as it were, for the real thing. However, in face-to-face interaction with unknown interlocutors, the language fulfils a function, solves a problem, provides an outcome. As the MFL student teachers at Cardiff High School found, "the stimulus of having to prepare for "publication" and "broadcast" is an excellent incentive for maximum effort and thought' (BT, 1997, 10). In this way, the work with the technology can be seen to be integrated into, indeed arise from, the normal curriculum work, and not as an extra, bolt-on activity. More significant, however, are the learning benefits that will have accrued in the process. Pupils will have developed skills of collaboration and autonomy, communication, and presentation. As Davis (1994) points out:

Information provided by pupils in another location is not mediated by the publishing process and such 'raw' data is frequently more relevant to the pupils than that in a textbook. The communication process becomes intense with participants focusing on both the immediate changes visible on the computer screen and the personal contact of the voice.

Hopkins $(1995,212)$ makes a similar point with reference to the use of interactive video with ISDN access for teaching English as a second language:

Because each student is effectively isolated from the rest of the class, he or she is forced to rely on the language to communicate effectively. In contrast, when physicallygrouped together messages can be sent with a shrug, grin or a groan, spontaneous 
native language exchanges are also likely. Properly used, the technology may actually enhance the teacher's ability to guide the student.

\section{Foreign-language learning}

It could, of course, be argued that our situation is still an artificial one. English-speaking pupils in Wales are communicating with English-speaking pupils in Scotland, who will be following a similar, if not identical, curriculum. The material exchanged will essentially be familiar, the topics covered the same, the language used will be pre-prepared and 'staged'. The experience of the student teacher at Glenwood High School, while linked with Cardiff High School, was that 'pupils did not revert to their native tongue when they got stuck, but she did find that the pupils relied on what they had already prepared to say and did not venture to ask questions' (BT, 1997, 17). She attributes this in part to the lack of true eyeto-eye contact due to the positioning of the videoconferencing camera. In other words, the very medium itself, while improving communication, was actually setting up another barrier, inhibiting spontaneity (in this context, see Jacobs and Rodgers, 1997). Selfconsciousness is not simply a product of the technology, however, and will undoubtedly be removed with increased use of the equipment. Let us underline the principle once more: the establishment of videoconference links between pupils studying languages provides a genuine purpose for oral communication that goes beyond that of the normal classroom.

The issue of authenticity is methodologically contentious in Modern Language teaching. Should one use raw, unedited, authentic source material in the target language, or should there be some element of pedagogic intervention, of tailoring content to suit the ability of the learner? Equally, should one make videoconferencing contact on the basis of familiar-ity of context and culture, i.e. English-speaking pupils communicating with English- speaking pupils, or opt instead for linking with the foreign country itself? In the absence of an established family-to-family exchange programme, C\&IT can clearly bring the foreign country directly into the classroom, providing a taste at least for those unable to travel or otherwise gain first-hand experience of the foreign culture. In this way French, German and other languages are seen as real languages, not simply as academic school subjects. While national links are perhaps an essential starting point, the future must lie with international developments. In any event, however, videoconferencing establishes face-to-face contact and realizes the potential for developing both oral and written skills, while bringing a vital touch of authentic culture into the classroom and providing an authentic audience for genuine communicative activity.

Further projects planned at Cardiff High School include the video-recording of scenes around the school with commentary in French, which will then be transmitted to pupils in Glenwood High School (once again it is apparent that this would have increased worth if the exchange were with a school in France). Also planned are exchanges of posters, postcards, and leaflets using fax, and personal letters, on a pen-pal basis, using email.

In a curriculum area that by definition has communication at its very core, it is self-evident that C\&IT has a central role to play in the teaching and learning of languages. In considering, in another context, the motivating factors behind an MFL Newspaper Day project, Davis (1994) observes:

Communication technology is one of the few ways to make external sources of input really meaningful in the confines of a Languages classroom. Pupils begin to see that they can have access to the real world of languages used for real purposes. 
Furthermore, it is not simply the medium and its intrinsic novelty that bring added motivation and realism to the learning process. The pedagogical benefits associated with the preparation of materials for a genuine audience have to do with pride in presentation, ownership of information, sharing, social interaction, sense of purpose.

A final example of the potential of the medium in the area of MFL is whiteboarding, a technique that can be used at any level. Using the software provided with the videoconference facility, a high degree of interaction can be achieved. For example, pupils in one school can give oral descriptions of themselves, which the receiving pupils can note down or draw. The all-too-familiar topic of Finding the Way Around Town can take on new life when pupils give directions to their link school which the receiving pupils follow on the screen, simultaneously learning something about a town they do not know. Visuals without text for a cartoon strip provided by one school can be completed with speech bubbles or captions by the other school. Inter-school surveys on favourite sports, hobbies, school subjects, or holidays will produce interesting contrasts and cultural comparisons, which can then be further processed into bar charts for display using other IT applications. There could be joint production of posters, classroom displays, quizzes, newspapers, school and town brochures, and, of course, games: noughts and crosses (practising numbers, letters, etc.), Bingo, Blockbusters.

\section{Teacher training and professional development}

While pupils' knowledge and skills will be enhanced in the ways mentioned above, there are major implications for student teachers' initial training. Indeed, the very title of the project (BT Initial Teacher Training Communication Technologies Initiative) recognizes this. By supporting partnerships between HEIs and schools, training and development is facilitated in four directions: to school pupils, student teachers, teachers, and university tutors. Let us next consider student teachers.

Student teachers are challenged to think of ways of managing language input and organizing pupils effectively to use technology in appropriate ways. In spite of pupils' relative confidence with information technology, one has still perhaps to beware of the 'Friday afternoon' syndrome, the tendency to regard the use of computers as 'a bit of fun', not real learning. Part of the training therefore involves a destigmatizing process, a fresh appraisal of attitudes (though this may well be more applicable to experienced teachers!). It is crucial to promote a spirit of critical reflection that enables teachers and student teachers to evaluate professionally the advantages and disadvantages of the technology, not to advocate its use for spurious reasons.

In the same way as pupils are required by the National Curriculum to be given opportunities to use information technology, so too should student teachers (DFE/WO, $1992,8)$. Until the present, this will have consisted largely of using subject-specific software (games, simulations, text manipulation packages, databases) and word-processing, but will now have to include C\&IT applications such as videoconferencing and email. There are clear resource implications for schools and HEIs here, obviously a potential obstacle to further development. It cannot be left to projects such as the BT initiative to supply a mere handful of schools and HEIs with the necessary hardware and experience that will eventually become an integral part of learning in the next century. 
While the use of the technology depends on availability, its application in the learning context will be as much a matter of organization and management as linguistic and pedagogical skills. Thus the arranging of pupils to prepare particular tasks, individually or in pairs or groups, the monitoring of the actual language content, the correction (if appropriate) of pronunciation and delivery or written outcome, will all be essential competences to be acquired. Somekh and Davies (1991) itemize in some detail what should constitute a revised agenda for some teacher training programmes. For example, in general, teachers should:

- set tasks, including but not only computer-mediated tasks, which require learners to engage in higher-order cognitive processes (e.g. synthesizing, analysing, reconstructing and creating on the basis of information and experience);

- reflect on students' learning (i.e. identifying specific learning outcomes from listening to talk, observing action, and evaluating with learners the results of their work);

- respond to students' needs as they emerge rather than pushing through a pre-specified teacher agenda;

- recognize that there is a necessary hiatus period when students are engaging in tasks involving problem-solving and decision-making, and restrain the desire to clarify the task too early.

Some may see this as a relinquishing of teacher control, an abandonment to the whims of the machine and the random indiscipline of play, but it is surely an inevitable consequence of such an exponential, and ultimately uncontrollable, source of learning. If, among many pedagogic by-products, there can be, for example, a shift in the balance of students' activities from laborious tasks, for example drawing graphs, to higher level tasks for example interpreting graphs (see Somekh and Davies, 1991), the enhancement to learning is self-evident. C\&IT will ipso facto contribute to greater autonomy in learning, not, as some would have it, replacing the teacher, but extending and enriching his/her role. In this context, the configuration of teacher, student and computer changes the traditional structure of teaching and learning in the classroom. As Somekh and Davies (1991) rightly note, the computer reduces the dependency of student on the teacher.

Not only can student teachers enhance pupils' learning by enabling them to prepare and share material, but they can also share ideas for teaching resources, lesson planning and so on, with their tutor or their counterparts in other HEIs and schools. Clearly, this latter use lends itself also to in-service training and consultations between university and school. Wright and Cordeaux (1996) summarize the dual outcomes of a videoconferencing project for student teachers as well as colleagues in school:

The student trial group [. . .] found greatest use of the technology in providing real time collaborative working which they did in exchanging lesson materials and plans and in creating two user guides for the technology. School colleagues are now using the technology for administration and support and [. . . ] for distance lesson observation.

It is interesting to compare in this connection the experiences of Open University PGCE students who, by means of the computer-conferencing software First Class, are able to 
communicate with other student teachers and their tutors, in a context that demands the use of distance-learning facilities. Admittedly, in this case the videoconferencing element is absent. Nevertheless, the value of the facility as a support and learning tool has been perceived to be fundamental. The NCET publication on teacher training and information technology (NCET, 1997) documents the following advantages identified by students:

they feel less isolated;

it helps them prepare for day schools and tutorials (pre-reading and agenda setting);

they can share good practice;

they can seek reassurance in a small group whose members they know well;

it is convenient since it is asynchronous;

they can easily pick up administration information.

Similarly, the facility can be used for consultations with university tutors, feedback on lessons, and written assignments - in short, remote supervision of any aspect of the training course. With visits by tutors to schools becoming less frequent, and the time pressure on teacher-mentors remaining a problem, this may well come to be seen as one of the single most beneficial, economic as well as educational, features of C\&IT. The work of the university tutor in education differs from that of other university teachers more accustomed to the lecture mode. For this reason, Laurillard (1993) sees little scope for videoconferencing as an interactive instrument for university teaching, regarding it as definitely a presentational and discursive medium. Inevitably, this fact is exploited by lecturers, and the potential interaction with students rarely occurs. Laurillard concludes that 'on balance, the two-way visual link is hard to justify in an educational context. The current technology makes it an uncomfortable way to negotiate a shared conception'(167). This is of course more of a criticism of the pedagogical limitations of the lecture format than a comment on videoconferencing as a whole, for while it is undeniable that a video would be a cheaper and easier way of transmitting a didactic lecture, the nature of the interaction between tutor and student teacher is of a very different order. Highly individualized and personal, overcoming the burdens of distance and time and responding to immediate needs, it in fact takes on something of the character of a vital lifeline.

The principle of 'timeshift', in which a video recording is made of a student teacher's lesson and is sent downline to the university tutor for joint evaluation, is a further example of the cost-effective deployment of resources. With improvements to digital video quality, this again may prove a vital support, especially to student teachers at risk of failing, and who need intensive additional advice. The flexibility to pinpoint specific actions, and to enable the student teacher to analyse his/her practice with freeze-frame evidence, is compelling and dynamic, although we have been aware, at Cardiff High School and at Swansea, of 'issues about which has the greatest effect on classroom behaviour, the presence of a visiting tutor or a video camera' (BT, 1997, 11), and would hope to reconcile this tension in future. Needless to say, such support can also be provided in written format using email or fax, but Davis (1997), for example, describes a 'conference' in which agenda points selected by the student teacher for the mentor to observe while the student taught, formed the basis of a supervisory session with the university tutor, and outlines the additional effectiveness of the videoconference link: 
Early work using multimedia telecommunications for the supervisory conference with the university tutor suggests that the telecommunication enhances the student's reflection. We think this may be because the student teacher recognises that he or she must take the lead in preparing for the supervisory conference, and because of this, and the individual focus of the telecommunications link, the student gains more insight into the process of teaching and learning.

As with school pupils, the question of whether the technology provides an enhancement to teaching and learning is almost a rhetorical one. The use of videoconferencing (and email) enables student teachers to provide pupils with a relevant and realistic outcome for the purposeful communication of language to a genuine target audience. It develops essential organizational and management skills, and provides a unique opportunity for communication at a distance with fellow student-teachers and university tutors, and consequent development of critical professionalism.

\section{Professional development}

What role does C\&IT have to play in the continuing professional development of teachers? Videoconferencing lends itself well to in-service training, previously conducted on site in school or at the university, but here obviating the need for travel and saving tutor's expenses and disruption to a teacher's day. The technology also allows the use of software applications such as PowerPoint for additional polish of presentation, rather than overhead transparencies. The very use of the videoconferencing equipment will provide the opportunity for otherwise perhaps inexperienced teachers to acquire competence in its use, and it thus fulfils a dual professional training purpose. Teachers can link up with colleagues in other schools and institutions to share ideas, resources, converse in the target language, in the same way as their pupils. The use of the facility for discussions between university tutors and senior mentors in schools, for example on matters which require elucidation in course programmes, particularly involving visual material, is manifestly highly valuable. The university tutor can also 'virtually' attend in-school seminars, once certain technical pre-requisites have been met. Here, as in any other new undertaking or one that relies on technical management, one should not be daunted by inevitable 'teething problems'. The potential of the medium far outweighs any false starts or slight inconvenience.

In the same way as there are statutory obligations upon student teachers and pupils to acquire information-technology capability, so too are existing qualified teachers judged, among other things, on the effective integration of information technology into their teaching: 'Standards achieved by pupils are to be determined by evaluating their competence in the key skills within reading, writing, speaking and listening, number and information technology, in the curriculum as a whole' (OFSTED, 1991). This will need to start with positive attitudes, not a grudging and sceptical tolerance, and extend to (NCET, 1995):

- an understanding of the educational potential of IT;

- an ability to use IT effectively in the curriculum;

- an ability to manage IT use in the classroom; 
- an ability to evaluate IT use;

- an ability to ensure differentiation and progression;

- a technical capability;

- issues of time, access, resources, training, and the status of IT;

Ultimately, however, professional development is concerned as much with personal empowerment as with prescription and uniformity of standards. Colleagues will appreciate the time-saving and cost-cutting possibilities for in-service training, workshops, lectures and talks opened up by telecommunication links, as well as the inevitable value of curricular project work with pupils as discussed above. The ability to access huge amounts of information, and to transform this into learning material revitalizes teaching, keeps the teacher up to date, and assists reflection and adaptability to change. In this connection, Somekh and Davies (1991) state that 'changing societies need to educate for change', and cite Dewey's vision of the kind of society in which transformation of educational processes is possible:

Particularly is it true that a society which not only changes but which has the ideal of such change as will improve it, will have different standards and methods of education from one which aims simply at the perpetuation of its own customs. (Dewey, 1961, 81)

\section{Conclusion}

In their wide-ranging, psychologically thoroughly-grounded paper that seeks to establish a model for a pedagogy for information technology, Somekh and Davies (1991) offer useful definitions of pedagogical competencies possessed by teachers and learners, which assume that:

- learning arises from active engagement of the learner;

- this engagement gives both teachers and learners cognitively active roles, since knowledge is constructed and reconstructed through heuristic processes of creative thinking and interaction, as well as the acquisition of appropriate information;

- the assessment of competence depends on listening, observing and responding to learners reflecting on their products (written or spoken); and on the exercise of judgement (including learners' judgements) within a coherent and explicit value system.

- Technology is contributing to the shift from a knowledge-based, teacher-transmission model of learning to one that is process-based, and learner-oriented. Wright and Cordeaux (1996) refer to 'a changed approach and understanding of the teaching and learning processes' which arise from the capacity of the technology for 'flexibility, intimacy, opportunities for real interaction and collaborative working in real time'. The learner can access information and knowledge from a variety of sources, including the teacher, but the assimilation and application of new knowledge is being transformed by the enormous power and potential of the technology. Somekh and Davies (1991) identify in this process a number of 'dimensions of pedagogic change' that involve a movement:

- from individualized to communicative learning; 
- from a view of the teacher's role as an organizer of learning activities to one as an enabler of quality learning experiences, using the minimum pre-specified structure;

- from a view of technology as either a tutor or a tool to one where it interacts in a variety of ways with learners, sometimes providing ideas, sometimes providing a resource for enquiry, and sometimes supporting creativity.

At the same time, and more pragmatically, pupils are being given the opportunities, as required by the National Curriculum, to develop their information technology capability and to use a range of resources for communicating. C\&IT can open the doors of the classroom to the world, enhancing and extending the curriculum for those involved in the teaching and learning process: pupils, student teachers, teachers, and teacher trainers. By providing a genuine focus for communicative language activity, videoconferencing (and email) develop not only oral (and written) skills, but technical and social competence, collaboration and autonomy. Student teachers develop organizational and management techniques, in addition to benefitting from remote supervision and the ability to reflect on and analyse the teaching and learning process and to construct new concepts of pedagogy. Teachers are enabled to redefine their role and explore the possibilities opened up by wider access to sources of information and knowledge. Teacher trainers can support student teachers and teachers without leaving their base - something which is particularly valuable in the days of school-based training. As Davis (1997) reminds us, communication is a fundamental process of education: "When the mode of communication changes, the organisation must change also'.

Our experience at Cardiff High School and the University of Wales Swansea has begun to change our organizations, and has provided us with valuable lessons in the potential of innovation, which we trust will soon become an entitlement for all.

\section{References}

BT (1997), Good Beginnings: Good Connections, BT Initial Teacher Training Communication Technologies Initiative, London: British Telecommunications plc.

Davis, N. (1994), 'Electronic communication' in Underwood, J. (ed), Computer-Based Learning: Potential into Practice, London: David Fulton Publishers, 41-58.

Davis, N. (1997), 'Do electronic communications offer a new learning opportunity in education?' in Somekh, B. and Davis, N. (eds), Using Information Technology Effectively in Teaching and Learning, London: Routledge, 167-80.

DFE/WO (1992) (Department for Education/Welsh Office), Circular No. $9 / 92$ / Circular No. $35 / 92$ Initial Teacher Training (Secondary Phase), London and Cardiff: Welsh Office.

(DFE/WO) (1995) (Department for Education/Welsh Office), Modern Foreign Languages in the National Curriculum, London: HMSO.

Dewey, J. (1961), 'The democratic conception in education', chapter 7 of Democracy and Education, New York: Macmillan (first published by Macmillan in 1916.). Cited in Somekh and Davies (1991), q.v.

Hopkins, G.L. (1995), The ISDN Literacy Book, Reading, MA: Addison-Wesley. 
Jacobs, G. and Rodgers, C., 'Remote teaching with digital video: a trans-national experience', British Journal of Educational Technology, 28 (4), 1997, 292-304.

Laurillard, D. (1993), Rethinking University Teaching. A Framework for the Effective Use of Educational Technology, London: Routledge.

Mason, R. (1994), Using Communications Media in Open and Flexible Learning, London: Kogan Page.

Mason, R. and Bacsich, P. (eds) (1994), ISDN Applications in Education and Training, London: Institution of Electrical Engineers.

NCET (1995) (National Council for Educational Technology), Training Today's Teachers in Information Technology. IT elements of Capability for Teachers, Coventry: NCET.

NCET (1996) (National Council for Educational Technology), Teacher Training and Computer Mediated Communications, Coventry: NCET.

NCET (1997) (National Council for Educational Technology), Teacher Education and IT, Coventry: NCET.

OFSTED (1991), Framework for the Inspection of Schools, London: HMSO.

Somekh, B. and Davies, R. (1991), 'Towards a pedagogy for information technology', Curriculum Journal, 2, (2), 153-70.

Wright, N. and Cordeaux, C. (1996), 'Rethinking video-conferencing: lessons learned from initial teacher education', Innovations in Education and Training International, 33 (4), 194-202. 